\title{
$A C L$ reconstruction with quadriceps tendon graft and press-fit fixation versus quadruple hamstring graft and interference screw fixation - a matched pair analysis after one year follow up
}

Ralph Akoto ${ }^{1,2,3}$, Malte Albers ${ }^{1}$, Maurice Balke ${ }^{1}$, Bertil Bouillon ${ }^{2}$ and Jürgen Höher ${ }^{1 *}$ (D)

\begin{abstract}
Background: The objective of the study was to compare the results of a primary anterior cruciate ligament reconstruction (ACLR) using the press-fit fixation technique for a quadriceps tendon (QT) graft to a standard quadrupled hamstring (HT) graft with interference screw fixation.

Methods: A retrospective cohort study with a 12-month follow up provided data for 92 patients. Exclusion criteria were accompanying ligament injuries and contralateral $\mathrm{ACL}$ injury. Patients who suffered a graft failure, which was defined as a side-to-side difference of $>3 \mathrm{~mm}$, or infection were rated 'D' according to the IKDC and excluded from further evaluation. Forty-six patients underwent primary ACLR using the press-fit fixation technique for autologous bone QT graft. These patients were matched in terms of age, gender, accompanying meniscus tear and cartilage injury to 46 patients who underwent standard HT graft with interference screw fixation. Patients were evaluated according to the Lachman test, Pivot-Shift test, IKDC score, Tegner score, Rolimeter measurements, one-leg hop test, thigh circumference and donor side morbidity.
\end{abstract}

Results: No significant differences in Tegner score $(p=0.9)$, subjective or objective IKDC score $(p=0.9 ; p=0.6)$, knee stability (Lachman Test $p=0.6$; Pivot-Shift Test $p=0.4$; Side-to-Side Difference $p=0.4$ ), functioning testing (One-Leg Hop Test $p=0.6$; Thigh Circumference $p=0.4$ ) or donor side morbidity $(p=0.4)$ were observed at the follow up. The Lachman test was negative for $85 \%$ of the QT group and 83\% of the HT group. The Pivot Shift Test was negative for $80 \%$ of the QT group and $85 \%$ of the HT group. The mean side-to-side difference was $1.6 \pm 0.2 \mathrm{~mm}$ in both groups. The one-leg hop test revealed a collateral-side jumping distance of $96.2 \pm 8.5 \%$ for the QT group and $95.5 \pm 8.5 \%$ for the HT group. The thigh circumference of the injured leg was $98.3 \pm 3.0 \%$ on the uninjured side in the QT group and $99.7 \pm 3.0 \%$ in the HT group. A knee walking test resulted in no discomfort for $90 \%$ of the QT group and $85 \%$ of the HT group. The graft failure rate was $7.3 \%$ in the QT group and $9.8 \%$ in the HT group.

Conclusion: QT grafts fixated using the press-fit technique are a reliable alternative for primary ACL surgery.

Keywords: ACL reconstruction, Quadriceps tendon, Press-fit fixation

\footnotetext{
* Correspondence: hoeher@sporttrauma-koeln.de

${ }^{1}$ Sports Clinic Cologne at Cologne Merheim Medical Center, Cologne,

University of Witten/Herdecke, Ostmerheimerstraße 200, D-51109 Cologne,

Germany

Full list of author information is available at the end of the article
}

(c) The Author(s). 2019 Open Access This article is distributed under the terms of the Creative Commons Attribution 4.0 International License (http://creativecommons.org/licenses/by/4.0/), which permits unrestricted use, distribution, and reproduction in any medium, provided you give appropriate credit to the original author(s) and the source, provide a link to the Creative Commons license, and indicate if changes were made. The Creative Commons Public Domain Dedication waiver (http://creativecommons.org/publicdomain/zero/1.0/) applies to the data made available in this article, unless otherwise stated. 


\section{Background}

Currently, the autologous hamstring tendon (HT) and the patellar tendon (PT) are the most commonly used grafts for primary anterior cruciate ligament reconstruction (ACLR) [1, 2]. Good clinical results for both grafts have been reported in the literature [3]. However, recent literature has shown that these grafts have some disadvantages. In a considerable proportion of patients, harvesting the patellar tendon leads to discomfort on the donor side [4, 5]. In addition, recent literature has shown that HT grafts have a higher risk of failure than do PT grafts [6-9]. Quadriceps tendon (QT) grafts are currently considered only a second choice graft, although its good biomechanical and biological characteristics has been demonstrated in several studies [10, 11]. Clinical studies comparing QT and PT grafts showed comparable clinical results but lower donor side morbidity for the QT graft [12-15]. For these reasons, QT grafts have been proposed as a promising alternative to the common grafts in ACLR surgery.

To our knowledge, until now, four studies have been published, which compared QT and HT grafts in primary ACLR [16-20], However results were inconsistent, therefore more data directly comparing this two grafts is necessary.

Press-fit fixation is an alternative to conventional interference screw fixation. Biomechanical studies demonstrated adequate primary stability with ultimate load to failure pull forces at least equal to published results for interference screws [21, 22]. Excellent clinical results for different grafts types fixated in press-fit technique were reported [23-27].

In comparison to interference screw fixation press-fit fixation techniques showed less bone tunnel widening $[28,29]$. To our experience in case revision surgery the bone tunnel management is less difficult.

\section{Hypothesis}

Primary ACLR using the press-fit technique to fixate QT grafts achieves comparable results to interference screw fixation and standard quadrupled HT grafts.

\section{Methods}

Between December 2010 and March 2013, 120 patients with primary ACL insufficiency were enrolled in the study. Patients were included in this study if they met the following criteria: (1) older than 18 years of age, (2) primary ACL surgery, (3) no concomitant ligament injury, (4) unilateral ACL injury, (5) no previous surgery on the effected knee, (6), no chondral lesion worse than Outerbridge grade 2, (8) clinically and MRI confirmed ACL rupture. According to the methodology of a previously published study, 60 patients underwent ACLR with the press-fit technique used to fixate QT grafts [28]. Sixty patients who underwent an ACLR with interference screw fixation
(PLDLLA; MEGAFIX ${ }^{\circ}$; Karl Storz AG) with a fourfold semitendinosus graft were selected as control group for a comparative matched-pair analysis. Matched pair criteria (age, presence of an accompanying meniscus tear or cartilage injury, additional meniscus or cartilage surgery), the surgeon performing the operation (senior author J.H.), graft selection (patients were free to choose the desired graft), the surgical techniques and the rehabilitation protocol were identical to the studies published in the apron [23, 28] Patients with accompanying ligament injuries (collateral ligaments or posterior cruciate ligaments) or contralateral ACL injury were excluded. Patients who suffered a graft failure or infection were rated as " $D$ " according to the International Knee Documentation Committee (IKDC) criteria and excluded from further evaluation.

\section{Surgical technique}

The surgical technique was described in detail in a study published in advance [28] .

\section{Postoperative evaluation}

Follow-up examinations were performed for the QT group $14 \pm 1.4$ months after ACLR and for the HT group at $13.7 \pm 2.5$ months after ACLR. The duration of the graft surgery was recorded for each patient.

Subjective and objective IKDC scores and Tegner activity level scores were measured. Knee stability was assessed with the Lachman test (possible results: negative, $1+, 2+$ and 3+), Pivot-shift Test (possible results: negative, $(+)$ glide, + and ++ ) and a Rolimeter (Aircast Europa $\mathrm{GmbH}$, Neubeuern, Germany) to perform instrumental laxity measurement. Graft failure was indicated by a side-to-side difference of more than $3 \mathrm{~mm}$ in the instrumental measurement.

In addition, a one-leg-hop test was performed and the thigh circumference $20 \mathrm{~cm}$ above the joint line was measured. To describe donor side morbidity after graft harvesting, a knee walking test with a four-point scoring system described by Kartus et al. was used [30].

\section{Statistics}

Statistical analysis was performed using the SPSS 24.0 software package (SPSS, Inc. Chicago, Illinois). A paired t-test was used to evaluate parametric data, and non-parametric data was evaluated using the Wilcoxon test. A $p$-value of $<0.05$ was assumed to be statistically significant. A post hoc power analysis was performed with $G^{*}$ Power 3.1.9.3 to assess the validity of the number of patients, based on the comparison of the mean Tegner score at the time of follow up and all other variables. With these effect sizes, an alpha of 0.05, and sample size of 41, a power ranging from 0.05 and 0.95 was calculated ( 0.05 for Tegner score and subjective IKDC, 0.08 for One-Leg Hop Test, 0.1 for donor side morbidity 
Table 1 Demographic data, accompanying injuries and complications of the included patients

\begin{tabular}{llll}
\hline & QT Group $(N=41)$ & HT Group $(N=41)$ & 32 \\
\hline Male & 32 & $28 \pm 10$ & \\
Mean age (years) & $29 \pm 10$ & $8(5 / 3)$ & 0.495 \\
Accompanying injuries & $8(6 / 2)$ & 2 & 0.485 \\
Meniscus (medial/lateral) & 3 & $4(9.8 \%)$ & 0.486 \\
Chondral lesions & & 2 & 0.694 \\
Complications & $3(7.3 \%)$ & 2 & 0.644 \\
Graft failure & 1 & $4.5 \pm 1.7$ & 0.556 \\
Contralateral ACL rupture & 1 & $86.9 \pm 11.8$ & 0.8 \\
Infection & $4.3 \pm 2.2$ & $0.01^{*}$ \\
Mean and SD [mm] & $96.6 \pm 12.0$ & \\
Duration of surgery (min) &
\end{tabular}

*Paired t-tests indicate a statistically significant difference in the duration of surgery. No statistically significant differences were found in terms of demographic data, accompanying injuries or complications. $Q T=$ Quadriceps tendon; $H T=$ Hamstring tendon

and objective IKDC, 0.7 for postoperative side-to-side difference, for 0.83 for thigh circumference, 0.84 for Pivot-Shift Test, 0.87 for Lachman Test, 0.95 for Duration of surgery).

\section{Results}

Seven patients who suffered a graft failure (three in the QT group, four in the HT group) and three patients who had an infection (one in the QT group, two in the HT group) were rated as "D" according to the IKDC criteria, and the matched pairs were excluded from follow-up examinations. In addition, the matched pairs for three cases of contralateral ACL rupture (one in the QT group, two in the HT group) and nine cases (three in the QT group, six in the HT group) that were lost to follow up were excluded. Three new matched pairs were formed from six patients (three in the QT group, three in the HT group) whose matched partner was excluded. Eighty-two patients (41 in the QT group, 41 in the HT group) were available for the one-year follow-up examination. No statistical differences were found between the two groups in terms of graft failure, infection, contralateral ACL rupture or accompanying meniscus and cartilage injuries. The QT group underwent statistically

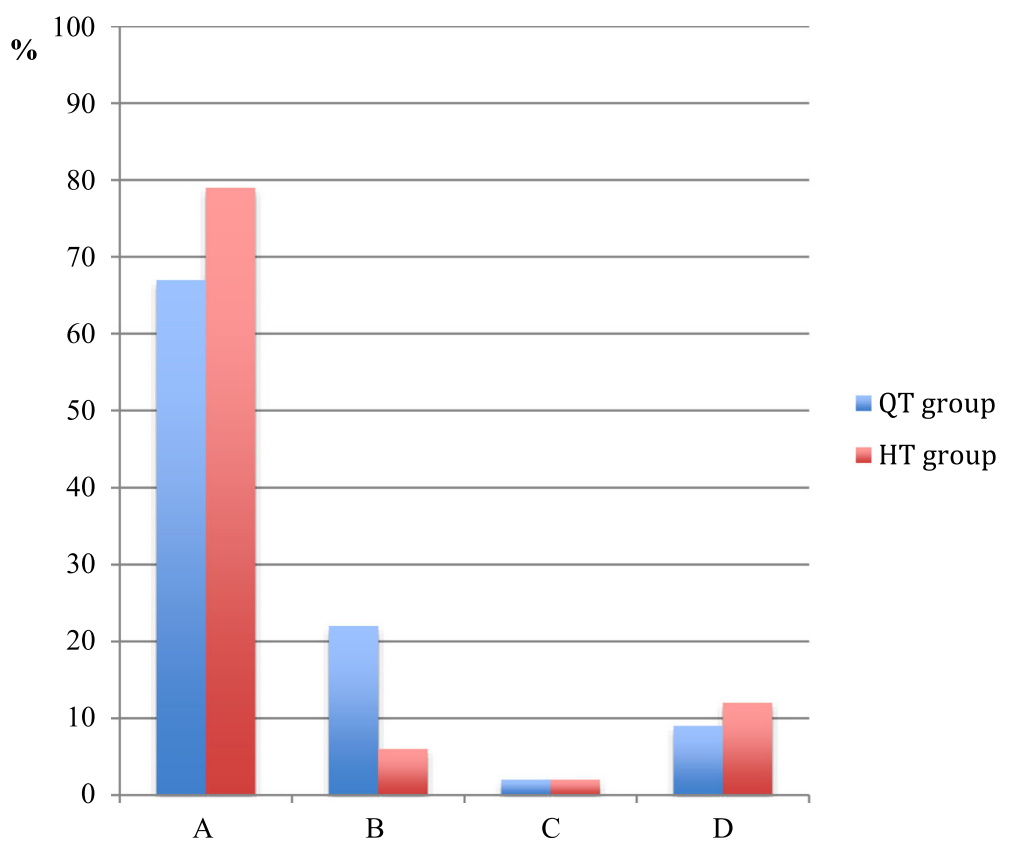

Fig. 1 Objective IKDC scores in percent of the QT group and the HT group at the time of follow up. No significant differences were found between the groups. $\mathbf{a}=$ normal; $\mathbf{b}=$ nearly normal; $\mathbf{c}=$ abnormal; $\mathbf{d}=$ severely abnormal 
Table 2 Postoperative knee stability (Lachman test, Pivot-Shift test)

\begin{tabular}{lllll}
\hline N & & QT group (\%) & HT group (\%) & p-value \\
& & 41 & 41 & \\
\hline Lachman Test & & & & 0.6 \\
& negative & $35(85)$ & $34(83)$ & \\
& + & $6(15)$ & $7(17)$ & \\
& ++ & 0 & 0 & 0.4 \\
Pivot-Shift Test & & & & \\
& negative & $33(80)$ & $35(85)$ & \\
& glide & $2(5)$ & $4(10)$ & \\
& + & $6(15)$ & $2(5)$ & \\
& ++ & 0 & 0 & \\
\hline
\end{tabular}

Wilcoxon test indicates no statistically significant difference between the QTand the HT group in objective knee stability (Lachman test, Pivot-Shift test) between the QT group and the HT group; $Q T=$ Quadriceps tendon; $H T=$ Hamstring tendon

significantly longer operations compared to the HT group.

Table 1 shows the demographic data from the baseline, accompanying injuries, complications and duration of operation for both groups.

\section{Functional scores}

No significant differences were found between the groups with regards to functional scores. The mean Tegner score at the time of follow-up was $7.6 \pm 1.8$ for both groups $(p=0.9)$.

The mean subjective IKDC scores were $86.4 \pm 14.2$ in the QT group and $86.7 \pm 10.9$ in the HT group $(p=0.9)$. The objective IKDC scores are shown in Fig. 1.

\section{Postoperative knee stability}

No significant difference between the groups was found regarding postoperative knee stability, measured by the Lachman test, Pivot-Shift test or instrumental measurement (Tables 2 and 3).

Functional tests (one-leg hop test and thigh circumference).

No statistical differences between the QT- and the HT group were found at the follow up regarding one-leg hop test results and thigh circumference (Table 4).

Table 3 Postoperative side-to-side difference (instrumental measurement, Rolimeter $\left.{ }^{\circledast}\right)$

\begin{tabular}{lllc}
\hline $\mathrm{N}$ & QT group & HT group & $p$-value \\
& 41 & 41 & \\
\hline Mean and SD [mm] & $1.6 \pm 0.2$ & $1.6 \pm 0.2$ & 0.8
\end{tabular}

Paired t-test indicates no statistically significant difference between the QTand the HT group in objective knee stability (instrumental measurement, Rolimeter $^{\otimes}$ ) between the QT group and the HT group. QT= Quadriceps tendon; $H T=$ Hamstring tendon
Table 4 One-leg hop test and thigh circumference

\begin{tabular}{lllc}
\hline $\mathrm{N}$ & QT group & HT group & p-value \\
& 41 & 41 & \\
\hline One-Leg Hop Test $^{\mathrm{a}}$ & $96.2 \pm 8.5$ & $95.5 \pm 8.5$ & 0.8 \\
Thigh Circumference $^{\mathrm{b}}$ & $98.3 \pm 3.0$ & $99.7 \pm 3.0$ & 0.2 \\
\hline a,b & & \\
per cent. Paired t-test indicated no statistically significant difference between \\
the QT- and the HT group. QT = Quadriceps tendon; $H T=$ Hamstring tendon
\end{tabular}

\section{Donor side morbidity}

In total, $90 \%$ of the QT group and $85 \%$ of the HT group had no discomfort when asked to walk on their knees at the follow up. No statistically significant differences were found between the groups $(p=0.4)$ (Fig. 2).

\section{Discussion}

The most important finding of this study is that a QT graft with press-fit fixation achieved comparable clinical and functional results as a standard HT graft with interference screw fixation.

Few previous studies have directly compared the clinical data of primary ACLR with QT grafts to that of ACLR with HT grafts, but the results are inconsistent (Table 5) [16-19].

Cavaignac et al. and Lee et al. reported the results of cohort studies comparing bone tendon QT graft and HT graft with 3.6 and 2 years follow up, respectively [17, 18]. Both authors achieved comparable results to our study regarding knee stability at the time of follow up (QT graft at FU: instrumental measurement $1.1 \pm 0.9 \mathrm{~mm}$ vs. $2.1 \pm 1.9 \mathrm{~mm}$ vs. $1.6 \pm 0.2 \mathrm{~mm}$ side-to-side difference; $93 \%$ vs. $67 \%$ vs. $80 \%$ negative pivot shift). Sofu et al. did not achieve similar results [19]. In their study, $21 \%$ of QT graft recipients suffered from persistent symptoms of knee instability, and only $48 \%$ had side-to-side difference of $<3 \mathrm{~mm}$. Sotu et al. justified these results, stating that the knee extensor was weakened, which increased the biomechanical stress of the graft and may have led to early graft failure. In our study, graft failure was defined as a side-to-side difference of $>3 \mathrm{~mm}$. Our definition of graft failure was stricter than that of Sofu et al. and other studies comparing QT and HT grafts. In our study, the failure rate of QT grafts was 7.3\%, which is much lower than that obtained by Sofu et al. and comparable to the results of Cavaignac et al., who reported 5 patients (11.4\%) with a side-to-side difference of $<3 \mathrm{~mm}$ at the follow up.

Concerning the results of the functional tests of this study, in the QT group, the participants achieved an average of $96 \%$ of hop distance with the injured legs compared to the uninjured legs in the one-leg hop test, and a mean calf circumference of $98 \%$ for the injuredcompared to the uninjured legs at the follow up. These results align with the isokinetic strength tests of Lee et 


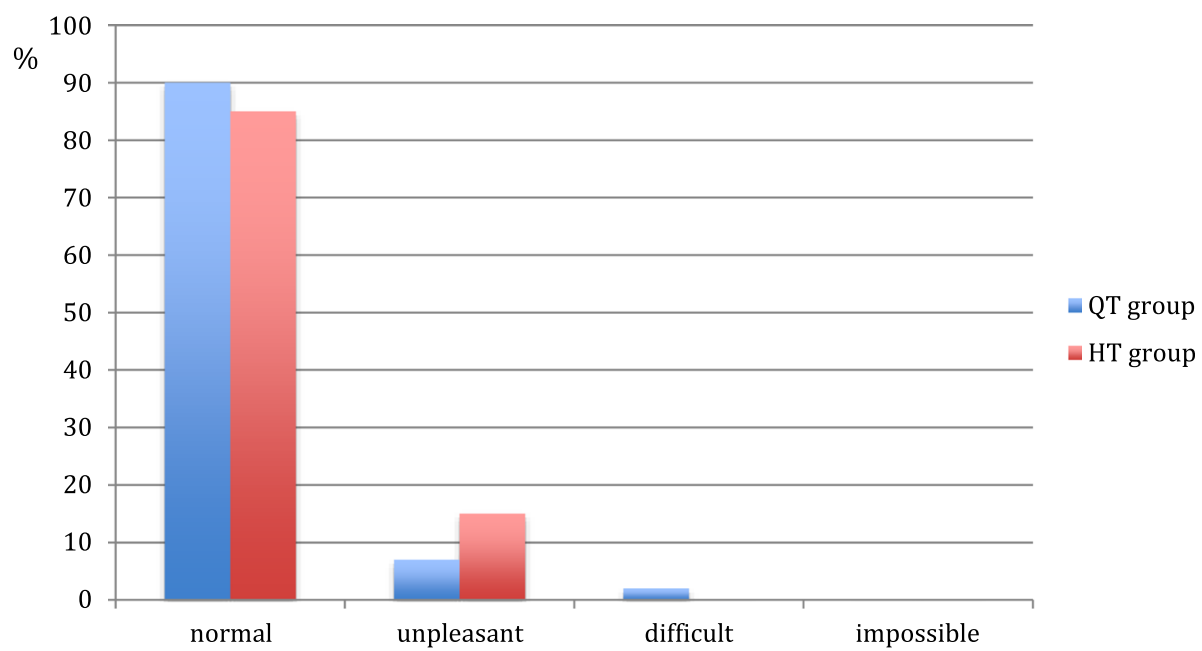

Fig. 2 Knee walking test of the QT group and the HT group at the time of follow up. The patients report their subjective discomfort in knee walking in the levels: no problems, minor problems, major problems or unable to perform the test. No significant differences were found between the groups

al., who reported no difference in knee extensor strength between QT and HT at follow up [18]. The results of Lee et al. as well as our findings shows that harvesting QTs does not led to biomechanical weakening of the knee extensor mechanism.

Studies examining donor side morbidity after harvesting grafts have found that QT grafts lead to significantly less anterior knee pain than do PT grafts [12-14, 31, 32]. To our knowledge, until now, the only authors to directly compare of donor side morbidity after harvesting QT and HT grafts were Runer et al., Cavaignac et al. and Lee et al. Like our study, all three studies revealed no significant difference in anterior knee pain between the two types of grafts [16-18].

In our study, grafts were fixated using the press-fit technique. Several studies have described the use of press-fit fixation techniques for ACL surgery [24-26, 33, 34]. In biomechanical investigations, press-fit fixation has shown sufficient strength, comparable to interference screw fixation [21]. For the tibial tunnel, we performed a hybrid technique involving press-fit fixation near the joint line and distal cortial suture fixation. In another study examining a subgroup of this study population, we show that this fixation technique leads to less bone tunnel dilation than interference screw fixation in the tibial tunnel [28].

Our results show that press-fit fixation for QT grafts could be an alternative to conventional fixation techniques. It is advantageous as it both saves fixation material, resulting in lower cost, and involves less bone tunnel enlargement, which could aid revision surgery.

\section{Limitations}

This study had several limitations. First, each group received a different graft fixation technique which may

Table 5 Clinical studies that directly compare ACLR with QT vs. HT

\begin{tabular}{|c|c|c|c|}
\hline Author & $\begin{array}{l}\text { Number of patients and Surgical Technique, FU } \\
\text { Drilling Technique Femoral/Tibial Fixation }\end{array}$ & Main Results & $\begin{array}{l}\text { Graft } \\
\text { Failure }\end{array}$ \\
\hline $\begin{array}{l}\text { Runer et al. } \\
{[16]} \\
2017\end{array}$ & $\begin{array}{l}40 \text { SB QT-PB vs. } 40 \text { SB HT; } 2 \text { years } \\
\text { Both: AM; button/Bio-IF screw + button }\end{array}$ & $\begin{array}{l}\text { No difference in Lyholm, Tegner and VAS scores or knee pain; no } \\
\text { postoperative knee laxity data }\end{array}$ & $\begin{array}{l}1 \mathrm{HT} \\
0 \mathrm{QT}\end{array}$ \\
\hline $\begin{array}{l}\text { Cavaignac } \\
\text { et al. [17] } \\
2017\end{array}$ & $\begin{array}{l}45 \text { QT-BT vs. } 41 \text { SB HT, } 3.6 \text { years } \\
\text { Both: outside in, Bio-IF screw/Bio-IF screw }\end{array}$ & $\begin{array}{l}\text { No difference in Tegner and IKDC scores; Sig. better Lysholm and KOOS scores } \\
\text { for QT; SSD QT-HT } 1.1 \mathrm{~mm} \text { vs. } 3.6 \mathrm{~mm}\end{array}$ & $\begin{array}{l}1 \mathrm{QT} \\
2 \mathrm{HT}\end{array}$ \\
\hline $\begin{array}{l}\text { Lee et al. } \\
{[18] 2016}\end{array}$ & $\begin{array}{l}48 \text { SB QT-PB vs. } 48 \text { dB HT, } 2 \text { years } \\
\text { QT: TT, metal IF screw/Bio-IF screw } \\
\text { HT: AM; button/Bio-IF screw }\end{array}$ & $\begin{array}{l}\text { No difference Lysholm, Tegenr, IKDC, SSD QT } 2.1 \mathrm{~mm} \text {; HT } 1.9 \mathrm{~mm} \text {; no } \\
\text { difference in anterior knee pain and extensor muscle strength recovery, better } \\
\text { flexor muscle strength recovery for QT }\end{array}$ & $\begin{array}{l}\text { No } \\
\text { data }\end{array}$ \\
\hline $\begin{array}{l}\text { Sofu et al. } \\
\text { [19] } 2017\end{array}$ & $\begin{array}{l}23 \text { SB QT-PB vs. } 21 \text { SB HT; both: TT, } 3 \text { years } \\
\text { QT: Metal-IF screw/Bio-IF screw } \\
\text { HT: Transfemural fixation/Bio-IF screw }\end{array}$ & $\begin{array}{l}\text { SSD: QT-HT } 2.8 \text { vs. 1.1, QT } 52 \%>3 \text { mm, HT } 9 \%>3 \text { mm } \\
\text { Symptoms of instability: } 21 \% \text { QT, } 0 \% \text { HT }\end{array}$ & $\begin{array}{l}\text { No } \\
\text { data }\end{array}$ \\
\hline
\end{tabular}

$F U=$ Follow up; $S B=$ Single bundle; $D B=$ Double bundle; $Q T=$ Quadriceps tendon, $P B=$ Patellar bone; $H T=$ Hamstring tendon; $A M=$ Anteromedial portal drilling technique; $T=$ Transtibial drilling technique; Bio-IF-screw = bioresorbable interference screw; $S S D=$ Side-to-side difference (KT1000/Rolimeter); $V A S=V i s u a l$ analogue scale; $K O O S=$ Knee injury and osteoarthritis outcome score; $A M=$ Anteromedial drilling technique, $Q T-B T=Q u a d r i c e p s$ bone-tendon graft 
have influenced the results. Nevertheless, previous studies have shown that press-fit fixation produces comparable results to conventional fixation techniques [24, 25, 33]. Second, some authors have stated that a follow up of 1 year after ACLR might be too short to evaluate postoperative outcomes. However, primary graft healing is complete after 12 months [35]. Third, the patients were free to choose the type of graft they received. This could have produced bias concerning the outcomes of our study. However, to produce comparable results, each patient in the QT group was matched to a patient in the HT group using the aforementioned criteria, all patients were the same gender and all procedures were done by one surgeon.

\section{Conclusion}

QT graft fixated with the press-fit technique achieved good results comparable to those of a standard HT graft with interference screw fixation. Thus, it is reliable alternative for primary ACL surgery.

\section{Abbreviations}

ACLR: Anterior cruciate ligament reconstruction; HT: Hamstring tendon; IKDC: International Knee Documentation Committee; PT: Patellar tendon; QT: Quadriceps tendon

\section{Acknowledgements}

The authors thank Rolf Lefering for supporting the statistical data analysis.

\section{Funding}

The study was neither funded financially nor materially.

\section{Availability of data and materials}

The datasets used and/or analysed during the current study are available from the corresponding author on reasonable request.

\section{Authors' contributions}

$\mathrm{RA}$, and $\mathrm{JH}$ designed the study. RA directed its implementation and wrote the paper. MA performed the data collection and the statistic analysis. MB and $B B$ helped to design the study's analytic strategy. MA, JH and MB reviewed the paper. All authors read and approved the final manuscript.

\section{Ethics approval and consent to participate}

This study was approved by the ethical committee of Witten/Herdecke University (Application No. 109/2010). Written informed consent was obtained from all study participants.

\section{Consent for publication}

Not applicable.

\section{Competing interests}

The authors declare that they have no competing interests.

\section{Publisher's Note}

Springer Nature remains neutral with regard to jurisdictional claims in published maps and institutional affiliations.

\section{Author details}

${ }^{1}$ Sports Clinic Cologne at Cologne Merheim Medical Center, Cologne, University of Witten/Herdecke, Ostmerheimerstraße 200, D-51109 Cologne, Germany. ${ }^{2}$ Department of Trauma and Orthopedic Surgery, University of Witten/Herdecke, Cologne Merheim Medical Center, Cologne, Germany. ${ }^{3}$ Department of Trauma and Reconstructive Surgery, Asklepios Clinic St. Georg, Hamburg, Germany.
Received: 28 April 2018 Accepted: 7 March 2019

Published online: 14 March 2019

\section{References}

1. MARS Group. Effect of graft choice on the outcome of revision anterior cruciate ligament reconstruction in the multicenter $\mathrm{ACL}$ revision study (MARS) cohort. Am J Sports Med. 2014:42(10):2301-10.

2. Shelton WR, Fagan BC. Autografts commonly used in anterior cruciate ligament reconstruction. J.Am Acad Orthop Surg. 2011;19(5):259-64.

3. Leys T, Salmon L, Waller A, Linklater J, Pinczewski L. Clinical results and risk factors for reinjury 15 years after anterior cruciate ligament reconstruction: a prospective study of hamstring and patellar tendon grafts. Am J Sports Med. 2012:40(3):595-605.

4. Ahn JH, Kim JG, Wang JH, Jung CH, Lim HC. Long-term results of anterior cruciate ligament reconstruction using bone-patellar tendon-bone: an analysis of the factors affecting the development of osteoarthritis. Arthroscopy. 2012;28(8):1114-23.

5. Kartus J, Movin T, Karlsson J. Donor-site morbidity and anterior knee problems after anterior cruciate ligament reconstruction using autografts. Arthroscopy. 2001:17(9):971-80

6. Mohtadi N, Chan D, Barber R, Paolucci EO. Reruptures, Reinjuries, and revisions at a minimum 2-year follow-up: a randomized clinical trial comparing 3 graft types for ACL reconstruction. Clinical journal of sport medicine : official journal of the Canadian Academy of Sport Medicine. 2016;26(2):96-107.

7. Schilaty ND, Bates NA, Sanders TL, Krych AJ, Stuart MJ, Hewett TE: Incidence of second anterior cruciate ligament tears (1990-2000) and associated factors by geographic locale. Am J Sports Med 2017:363546517694026.

8. Samuelsen BT, Webster KE, Johnson NR, Hewett TE, Krych AJ. Hamstring autograft versus patellar tendon autograft for $\mathrm{ACL}$ reconstruction: is there a difference in graft failure rate? A meta-analysis of 47,613 patients. Clin Orthop Relat Res. 2017

9. Gifstad T, Foss OA, Engebretsen L, Lind M, Forssblad M, Albrektsen G, Drogset JO. Lower risk of revision with patellar tendon autografts compared with hamstring autografts: a registry study based on 45,998 primary ACL reconstructions in Scandinavia. Am J Sports Med. 2014;42(10):2319-28.

10. Rabuck SJ, Musahl V, Fu FH, West RV. Anatomic anterior cruciate ligament reconstruction with quadriceps tendon autograft. Clin Sports Med. 2013; 32(1):155-64.

11. Xerogeanes JW, Mitchell PM, Karasev PA, Kolesov IA, Romine SE. Anatomic and morphological evaluation of the quadriceps tendon using 3dimensional magnetic resonance imaging reconstruction: applications for anterior cruciate ligament autograft choice and procurement. Am J Sports Med. 2013:41(10):2392-9.

12. Geib TM, Shelton WR, Phelps RA, Clark L. Anterior cruciate ligament reconstruction using quadriceps tendon autograft: intermediate-term outcome. Arthroscopy. 2009;25(12):1408-14.

13. Gorschewsky O, Klakow A, Putz A, Mahn H, Neumann W. Clinical comparison of the autologous quadriceps tendon (BQT) and the autologous patella tendon (BPTB) for the reconstruction of the anterior cruciate ligament. Knee Surg Sports Traumatol Arthrosc. 2007;15(11):1284-92.

14. Han HS, Seong SC, Lee S, Lee MC. Anterior cruciate ligament reconstruction : quadriceps versus patellar autograft. Clin Orthop Relat Res. 2008;466(1):198-204.

15. Kim SJ, Kumar P, Kim SH. Anterior cruciate ligament reconstruction in patients with generalized joint laxity. Clin Orthop Surg. 2010;2(3):130-9.

16. Runer A, Wierer G, Herbst E, Hepperger C, Herbort M, Gfoller P, Hoser C, Fink $C$. There is no difference between quadriceps- and hamstring tendon autografts in primary anterior cruciate ligament reconstruction: a 2-year patient-reported outcome study. Knee Surg Sports Traumatol Arthrosc. 2017.

17. Cavaignac E, Coulin B, Tscholl P, Nik Mohd Fatmy N, Duthon V, Menetrey J: Is quadriceps tendon autograft a better choice than hamstring autograft for anterior cruciate ligament reconstruction? Am J Sports Med 2017: 3635465166886655

18. Lee JK, Lee S, Lee MC. Outcomes of anatomic anterior cruciate ligament reconstruction: bone-quadriceps tendon graft versus double-bundle hamstring tendon graft. Am J Sports Med. 2016;44(9):2323-9.

19. Sofu H, Sahin V, Gursu S, Yildirim T, Issin A, Ordueri M. Use of quadriceps tendon versus hamstring tendon autograft for arthroscopic anterior cruciate ligament reconstruction: a comparative analysis of clinical results. Eklem Hastalik Cerrahisi. 2013;24(3):139-43. 
20. Fischer F, Fink C, Herbst E, Hoser C, Hepperger C, Blank C, Gfoller P. Higher hamstring-to-quadriceps isokinetic strength ratio during the first postoperative months in patients with quadriceps tendon compared to hamstring tendon graft following $A C L$ reconstruction. Knee Surg Sports Traumatol Arthrosc. 2017.

21. Dargel J, Schmidt-Wiethoff R, Schneider T, Bruggemann GP, Koebke J. Biomechanical testing of quadriceps tendon-patellar bone grafts: an alternative graft source for press-fit anterior cruciate ligament reconstruction? Arch Orthop Trauma Surg. 2006;126(4):265-70.

22. Arnold MP, Burger LD, Wirz D, Goepfert B, Hirschmann MT. The biomechanical strength of a hardware-free femoral press-fit method for $\mathrm{ACL}$ bone-tendon-bone graft fixation. Knee Surg Sports Traumatol Arthrosc. 2017:25(4):1234-40.

23. Akoto $R$, Hoeher J. Anterior cruciate ligament (ACL) reconstruction with quadriceps tendon autograft and press-fit fixation using an anteromedial portal technique. BMC Musculoskelet Disord. 2012;13:161.

24. Boszotta H. Arthroscopic anterior cruciate ligament reconstruction using a patellar tendon graft in press-fit technique: surgical technique and followup. Arthroscopy. 1997;13(3):332-9.

25. Barie A, Kargus S, Huber J, Schmitt H, Streich NA. Anterior cruciate ligament reconstruction using quadriceps tendon autograft and press-fit fixation. Unfallchirurg. 2010;113(8):629-34.

26. Hertel P, Behrend H, Cierpinski T, Musahl V, Widjaja G. ACL reconstruction using bone-patellar tendon-bone press-fit fixation: 10-year clinical results. Knee Surg Sports Traumatol Arthrosc. 2005;13(4):248-55.

27. Barie A, Kopf M, Jaber A, Moradi B, Schmitt H, Huber J, Streich NA. Longterm follow-up after anterior cruciate ligament reconstruction using a pressfit quadriceps tendon-patellar bone autograft. BMC Musculoskelet Disord. 2018;19(1):368

28. Akoto R, Muller-Hubenthal J, Balke M, Albers M, Bouillon B, Helm P, Banerjee $\mathrm{M}$, Hoher J. Press-fit fixation using autologous bone in the tibial canal causes less enlargement of bone tunnel diameter in ACL reconstruction--a CT scan analysis three months postoperatively. BMC Musculoskelet Disord. 2015;16:200

29. Kim SJ, Bae JH, Song SH, Lim HC. Bone tunnel widening with autogenous bone plugs versus bioabsorbable interference screws for secondary fixation in ACL reconstruction. J Bone Joint Surg Am. 2013:95(2):103-8.

30. Kartus J, Ejerhed L, Sernert N, Brandsson S, Karlsson J. Comparison of traditional and subcutaneous patellar tendon harvest. A prospective study of donor site-related problems after anterior cruciate ligament reconstruction using different graft harvesting techniques. Am J Sports Med. 2000;28(3):328-35.

31. Lund B, Nielsen T, Fauno P, Christiansen SE, Lind M. Is quadriceps tendon a better graft choice than patellar tendon? A prospective randomized study. Arthroscopy. 2014;30(5):593-8.

32. Kim SJ, Kumar P, Oh KS. Anterior cruciate ligament reconstruction: autogenous quadriceps tendon-bone compared with bone-patellar tendonbone grafts at 2-year follow-up. Arthroscopy. 2009;25(2):137-44.

33. Felmet $\mathrm{G}$. Implant-free press-fit fixation for bone-patellar tendon-bone ACL reconstruction: 10-year results. Arch Orthop Trauma Surg. 2010;130(8):985-92.

34. Paessler HH, Mastrokalos DS. Anterior cruciate ligament reconstruction using semitendinosus and gracilis tendons, bone patellar tendon, or quadriceps tendon-graft with press-fit fixation without hardware. A new and innovative procedure. Orthop Clin North Am. 2003;34(1):49-64.

35. Frosch KH, Sawallich T, Schutze G, Losch A, Walde T, Balcarek P, Konietschke F, Sturmer KM. Magnetic resonance imaging analysis of the bioabsorbable Milagro interference screw for graft fixation in anterior cruciate ligament reconstruction. Strategies Trauma Limb Reconstr. 2009;4(2):73-9.

\section{Ready to submit your research? Choose BMC and benefit from:}

- fast, convenient online submission

- thorough peer review by experienced researchers in your field

- rapid publication on acceptance

- support for research data, including large and complex data types

- gold Open Access which fosters wider collaboration and increased citations

- maximum visibility for your research: over $100 \mathrm{M}$ website views per year

At BMC, research is always in progress.

Learn more biomedcentral.com/submissions 